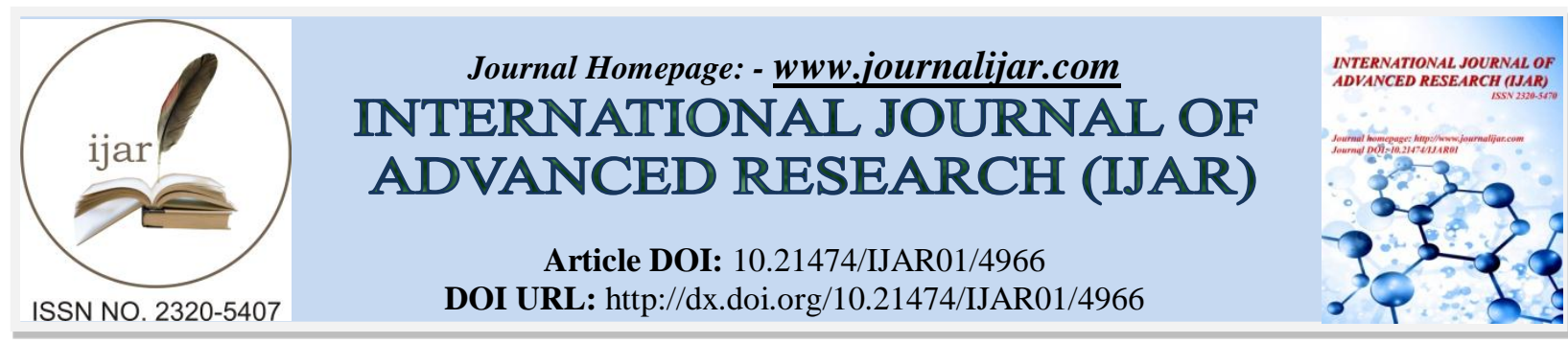

RESEARCH ARTICLE

\title{
DEVELOPMENT OF FABRICATION MATERIALS FOR LOW COST HOUSING USING SISAL FIBERS COMPOSITE.
}

Mr Prafull Patil and Dr. Prashant.M Pawar.

Civil Engineering, SVERI'S College of Engineering, Pandharpur.

\section{Manuscript Info}

(.........................

Manuscript History

Received: 26 May 2017

Final Accepted: 28 June 2017

Published: July 2017

\section{Abstract}

The present work deals with the effect of orientation on tensile, compression and impact properties on sisal fibers oriented composite. Tensile, Compression and impact tests are conducted for the composite and the results exhibit an enhancement in the structural property.in this work we will Develop the sisal fibers composite material like Box, Rod, and panels which are then used for low cost Hosing material as roof . By using epoxy chemical in fabrication of sisal fibers composite we get the hardness in that particular panel

Copy Right, IJAR, 2017,. All rights reserved.

\section{Introduction:-}

Sisal fibers are obtained from leaves of the plant Agave Sisalana, is species of Agave native to southern Mexico but widely cultivated and naturalized in many other countries. Emphasis on the development of new materials and technology has been there for the past few decades, in developing countries like India, so that the 'overall cost' of construction becomes affordable by the people. Further, countries like India have a social obligation of providing shelter to all, which they strive very hard to fulfill within a reasonable time. If overall economy in the construction of shelter

Especially to economically weaker sections of society is to be achieved, then, economy in each major component of shelter, to the extent possible has to be realized. Roof is one of the main buildings

Element, consumes about $20 \%$ of the total cost of construction. Asbestos cement based roofing and other light roofing materials are very commonly used in the construction of houses and industrial building, not only in India, but all over the other countries of the world also. In spite of the fact that asbestos-based roofing elements and products pose health hazards, ban on their use has not been effectively enforced. However, their exit alternate fibers, which have the potential for use in roofing materials. E.g., fibers from plants, such as sisal having several advantages like abundant availability, less costly and does not pose health hazard, and hence, can be used to develop various pozzolanas, flyash, is abundantly available in several countries and also in India. In India, sisal fibers are also abundantly available. Hence, there is scope and a necessity to investigate the role sisal fibers composites and products. 


\section{Methodology:- \\ Materials \\ Sisal fibre and its extraction:-}

Sisal (Agave sisalana) plants are more familiar with the tropics and subtropics region as they can grow better at a temperature more than $25^{\circ} \mathrm{C}$. These plants consist of sword shaped leaves of normally $1.5 \mathrm{~m}$ height and a typical plant produces around 150 leaves during its life span of 6 years. It contains about 500-800 fibers, which are normally used to make ropes, carpets etc. The matured leaves standing at an angle of more than $45_{-}$to the upright of the plant are cut. The next stage in which the leaves are initially crushed by the rollers of rounded knife edges followed by repetitive beaten is called decortication. During this process, the fibers are extracted by squeezing out the pulpy content of the leaf. Finally the fibers are dried in sunlight for 3-4 days after washing them in clean water to remove the dusts and unwanted contents in it.

\section{Epoxy:-}

Epoxy resin is a member of the epoxy oligomer class. It forms a three dimensional structure when it reacts with the hardener or curing agent. It is possible to change the properties of the epoxy resin with different epoxy oligomers and by choosing various curing agents. The epoxy-LY556 i.e., diglycidyl ether of biphenyl- A (DGEBA) with the hardener HY951 i.e., triethylenetetramine (TETA) is used as matrix material. The blending ratio of the resin with the hardener is 100:30 by weight.

\section{Laminate}

When there is a single ply or a lay-up in which all of the layers or plies are stacked in the same orientation, the layup is called a lamina. When the plies are stacked at various angles, the lay-up is called a laminate. Continuous-fiber composites are normally laminated materials (Fig. 1.7) in which the individual layers, plies, or lamina are oriented in directions that will enhance the strength in the primary load direction. Unidirectional $\left(0^{\circ}\right)$ laminate are extremely strong and stiff in the $0^{\circ}$ direction. Composites are rarely used in the form of unidirectional laminates, since one of their great merits is that the fibres can be arranged so as to give specific properties in any desired direction. Thus, in any given structural laminate, predetermined proportions of the unidirectional plies will be arranged at some specific angle, $\theta$, to the stress direction. In order to calculate the properties of such a multi-ply laminate, it is first necessary to know how the elastic response of a single unidirectional lamina, such as that which we have been considering so far, will vary as the angle to the stress direction is changed. However, they are very weak in the $90^{\circ}$ direction because the load must be carried by the much weaker polymeric matrix. Because the fiber orientation directly impacts mechanical properties, it seems logical to orient as many of the layers as possible in the main load-carrying direction.

\section{Composite preparation:-}

The composite laminates for this work were fabricated by compression molding method. Initially, the qualified sunlight dried sisal fibers are segregated and chopped. Different kinds of laminates were prepared with like 3 No of strip of size $16 \mathrm{~cm} \mathrm{X} 4 \mathrm{~cm}, 3$ laminate of $30 \mathrm{~cm} \mathrm{X} \mathrm{30cm} \mathrm{size,} 5$ No of sisal composite beam of size $20 \mathrm{~cm} \mathrm{X} 2.4 \mathrm{~cm}$, 3 no of sisal fibre composite for bonding strength .sisal fibers, $20 \mathrm{~cm} \mathrm{X} 50 \mathrm{~cm}$ panel and the epoxy resin were taken, the appropriate hardness also selected to fabricate the composites. The dimension of the mold used in the present work was $30 \mathrm{~cm} \mathrm{X} 30 \mathrm{~cm} 0.8 \mathrm{~cm}$. This had to be placed over the fixed bottom jaw after placing a polythene sheet over it to avoid deposition of squeezing resin during the process. The mixture of epoxy resin with the hardener was applied to the mold, and then it was followed by the uniform deposition of the natural fiber premixed with a predetermined percentage of the resin mixture on the mold according to the laminates needed. Finally the resin was applied at the top before compressing the laminate with the Loading material. The pressure was applied gradually to ensure uniform distribution of resin throughout the laminate and also to remove the entrapped air. The laminate was kept under constant pressure for about nearly $24 \mathrm{hr}$ to guarantee absolute curing After acquiring the compressed laminate from the Loading material, the burs on the rough edges were cut by using saw cutter and emery sheets were used to remove the rough edges.

Similar type of plywood panel is prepared by cutting with above size to compare. 


\section{Structural Testing:-}

Impact Resistance:-

The composite sheet of $30 \mathrm{~cm}$ x $30 \mathrm{~cm}$ and thickness $8 \mathrm{~mm}$ was tested using a Impact test setup. This setup contains steel ball and dial gauge. The panel is simply supported at four corners. The steel ball of $5 \mathrm{~cm}$ diameter and weight $450 \mathrm{gm}$. is dropped from $100 \mathrm{~cm}$ height.

Same test is carried out on standard plywood of thickness $8 \mathrm{~mm}$ with similar boundary condition. the impact test on plywood and Sisal fibre Composite panel. Table 2.4.1 shows the deflection of plywood at 5 different points similarly table 3.4 shows the deflection of Sisal fibre Composite panel at 5 different points. The average deflection in plywood is $2.78 \mathrm{~mm}$ whereas average deflection in Sisal fibre Composite sheet is $5.53 \mathrm{~mm}$ which is about 3 times that of deformation in plywood

Table 2.4.1:- Avg. deflection after impact.

\begin{tabular}{|c|c|c|}
\hline Point No. & $\begin{array}{l}\text { Deflection in mm } \\
\text { Sisal composite }\end{array}$ & Deflection in mm Plywood \\
\hline 1 & 5.4 & 2.7 \\
\hline 2 & 5.7 & 2.5 \\
\hline 3 & 5.6 & 2.8 \\
\hline 4 & 5.4 & 3.1 \\
\hline Average Deflection & 5.53 & 2.78 \\
\hline
\end{tabular}

\section{Bending Test:-}

The Sisal fibre composite panels are prepared in size $20 \mathrm{x} 50 \mathrm{~cm}$ and plywood sheets of same size are prepared. These panels are tested under Flexural Testing Machine so as to calculate the bending strength and deflection of both the panels. The deflection is measured by using the Dial Gauges of $0.01 \mathrm{~mm}$ least count.

The panels fabricated are tested under the FTM to measure the maximum load it can sustain under the bending. Thus using the parameters such as Load and Deflection of the tested panel the Flexural rigidity is calculated.

Fig.2.4.1:- Sisal fibre Composite after applying load.

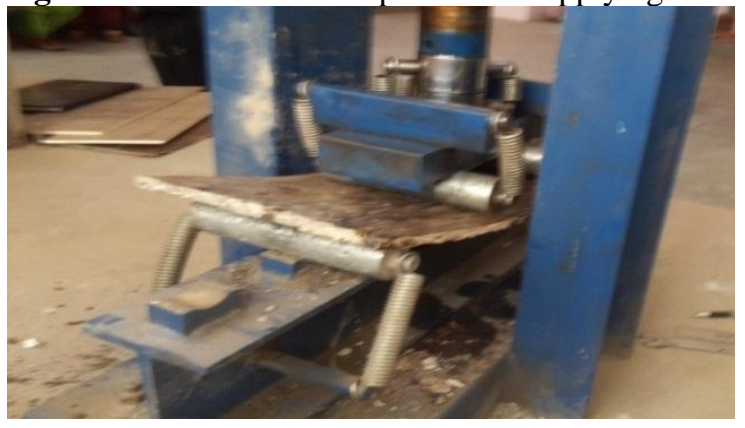

Fig.2.4.2;- Plywood after applying load

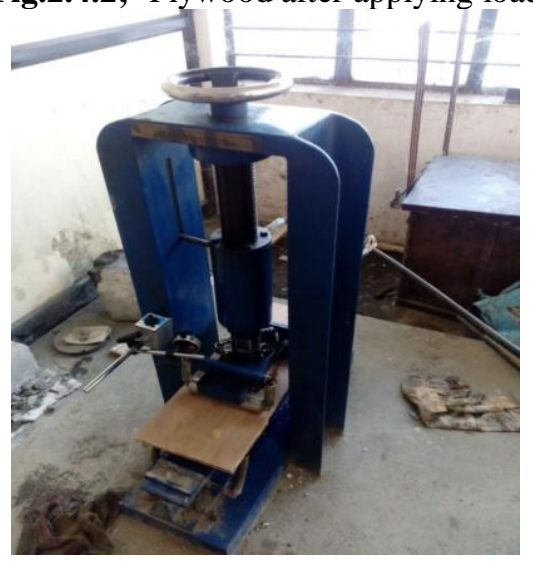


Table 2.4.2:- Load and Deflection for Sisal Fibre Composite

\begin{tabular}{|c|c|c|c|}
\hline Sr No. & Load in KN & Deflection in mm & Flexural rigidity $^{\text {in Nm }}{ }^{2}$ \\
\hline 1 & 9 & 35 & 257.14 \\
\hline 2 & 8.1 & 31 & 261.29 \\
\hline 3 & 7.6 & 27 & 281.48 \\
\hline
\end{tabular}

Table 2.4.3:- Load and Deflection for Plywood panel.

\begin{tabular}{|c|c|c|c|}
\hline Sr No. & Load in KN & Deflection in $\mathrm{mm}$ & Flexural rigidity $^{\text {in Nm }}{ }^{2}$ \\
\hline 1 & 3 & 10 & 300 \\
\hline 2 & 2.8 & 9.4 & 297.87 \\
\hline 3 & 3.2 & 10.2 & 313.72 \\
\hline
\end{tabular}

\section{Axial Strength in Tension for Sisal composite strip:-}

The Sisal fibre Composite strips of size $16 \mathrm{~cm} \mathrm{x} 4 \mathrm{~cm}$ are fabricated using Sisal fibre Composite pulp. The strips are sundried and then tested under axial loading on Universal Testing Machine. The plates are tested for different thickness viz. 0.9, 0.8. The strips are provided with holes so as to get anchorage and proper axial tensile force. After applying the tensile load, the Load and displacements are measured and using the slope equation Young's modulus is determined.

Fig 2.4.3:- Strips for determining Axial strength

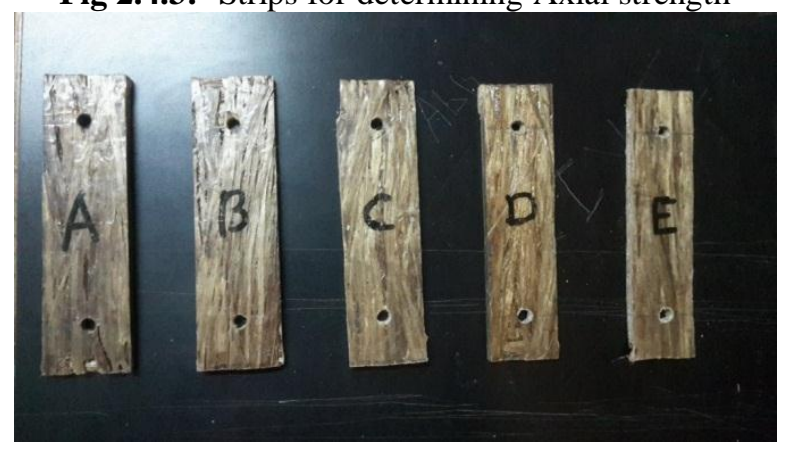

Table 2.4.4:- Axial Strength determination of Sisal fibre Composite.

\begin{tabular}{|c|c|c|c|c|c|c|}
\hline Sr. No. & $\begin{array}{c}\text { Wt of specimen } \\
\text { (gms) }\end{array}$ & Length (cm) & Width (cm) & Thickness (cm) & $\begin{array}{c}\text { Initial gauge } \\
\text { length }\end{array}$ & $\begin{array}{c}\text { Final } \\
\text { gauge } \\
\text { length }\end{array}$ \\
\hline A & 69.5 & 16 & 4 & 0.9 & 113 & 117 \\
\hline B & 67.1 & 16 & 4 & 0.95 & 113 & 115 \\
\hline C & 69.5 & 16 & 4 & 0.8 & 113 & 116 \\
\hline
\end{tabular}

Fig 2.4.1:- Load v/s Displacement graph for Sample No. A :

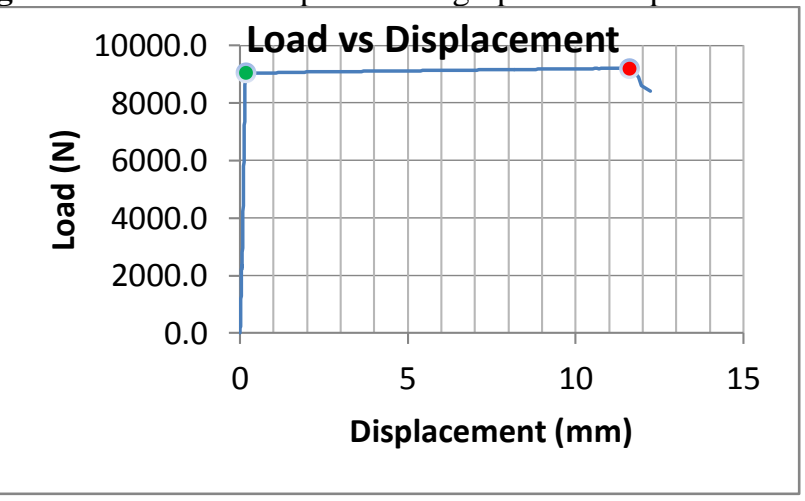


The yield load $=9041 \mathrm{~N}$

Displacement $=12.23 \mathrm{~mm}$

Stress at Yield $=25.41 \mathrm{~N} / \mathrm{mm}^{2}$

Strain at yield $=0.0036$

So, The young's Modulus $(\mathrm{E})=7058.33 \mathrm{~N} / \mathrm{mm}^{2}$

\section{Axial Strength in Tension for Sisal composite beam:-}

The Sisal fibre Composite beam of size $20 \mathrm{~cm} \times 2.4 \mathrm{~cm}$ are fabricated using Sisal fibre . The beams are tested under axial loading on Universal Testing Machine. The beams are tested for thickness viz. 1.9, 1.8. The strips are provided with holes so as to get anchorage and proper axial tensile force. After applying the tensile load, the Load and displacements are measured and using the slope equation Young's modulus is determined.

Fig 2.4.4;- Beam at the time of axial strength test

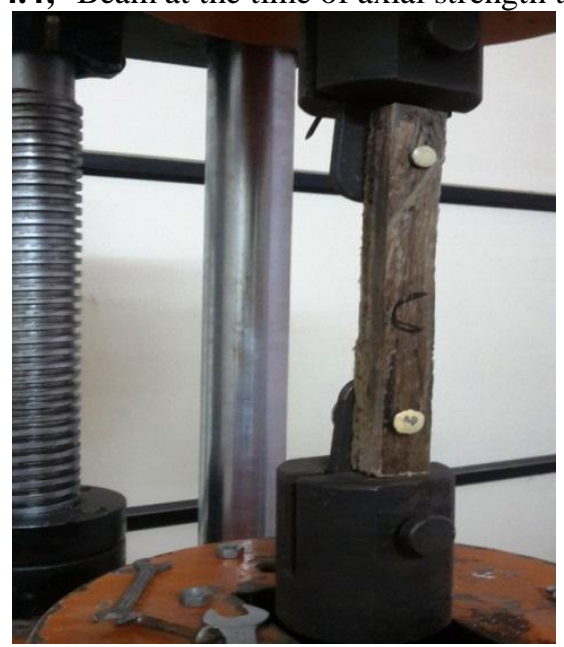

Table 2.4.5:- Axial Strength determination of Sisal fibre Composite.

\begin{tabular}{|c|c|c|c|c|c|c|}
\hline Sr. No. & $\begin{array}{c}\text { Weight of } \\
\text { specimen (gms) }\end{array}$ & Length (cm) & Width (cm) & Thickness (cm) & $\begin{array}{c}\text { Initial gauge } \\
\text { length }\end{array}$ & $\begin{array}{c}\text { Final gauge } \\
\text { length }\end{array}$ \\
\hline A & 90.8 & 20 & 2.4 & 1.90 & 148 & 151 \\
\hline B & 72.3 & 20 & 2.4 & 1.83 & 148 & 153 \\
\hline C & 86.2 & 20 & 2.4 & 1.80 & 148 & 151 \\
\hline
\end{tabular}

Fig 2.4.2:- Load v/s Displacement graph for Sample No. C:

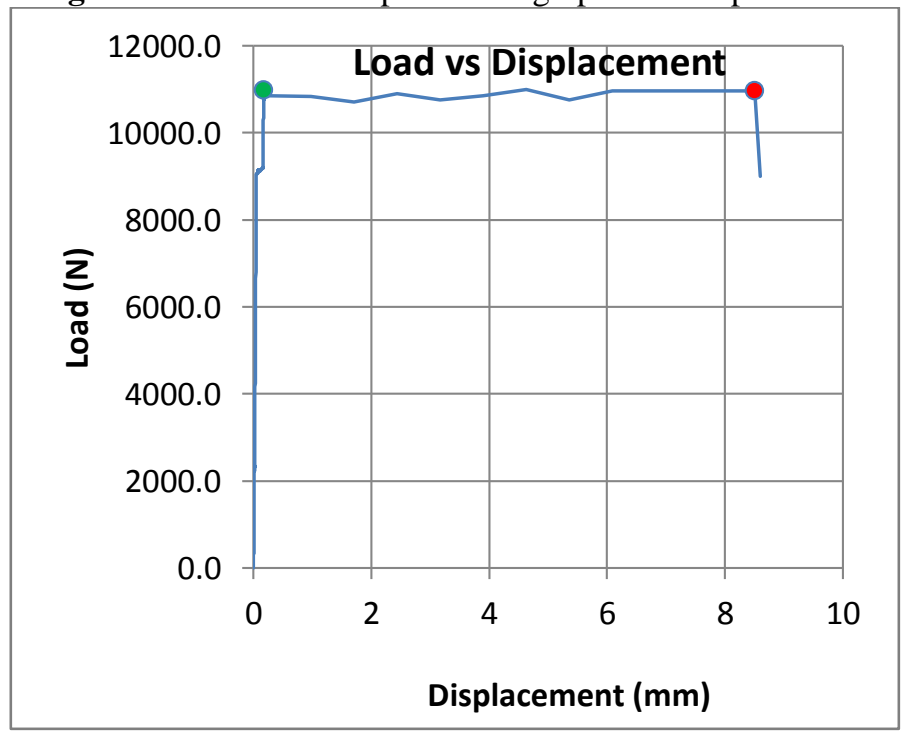




\section{Conclusions:-}

- The panels fabricated using Sisal fibre Composite exhibit more strength, Impact resistance and flexibility as compared to the plywood of same size and thickness. The deflection developed in the Sisal fibre Composite panel was more as compared to the plywood but there were no cracks developed at the point of maximum deflection.

- The panels are acid and alkali resistant and do not exhibit any blister when it comes in contact of any acid or alkalis. Whereas, the plywood of same size and thickness showed blister at its surface when it was kept in contact with acid for $24 \mathrm{hrs}$.

- The panels are very good in Sound Absorption as compared to the plywood. When sound was passed through the Sisal fibre Composite panel and the plywood, the Sisal fibre Composite panel shows 37\% more sound absorption capacity.

- The materials used in fabrication of Sisal fibre Composite panels are of much cheaper cost. The panels cost almost $20 \%$ less than plywood of same thickness. The per square $\mathrm{ft}$ rate of Sisal fibre Composite panel is $42 \mathrm{Rs}$ whereas plywood of same thickness costs 54 Rs per square $\mathrm{ft}$.

\section{Acknowledgment:-}

The structural properties of sisal fibre composite were studied in this work. The laminates were manufactured by the compression molding process and tested. From the obtained results, the above conclusion are derived

\section{References:-}

1. P. Parandaman and M. Jayaraman Department of Mechanical Engineering, Paavai Engineering College, Namakkal, Tamil Nadu, India and Department of Mechanical Engineering, Velalar College of Engineering and Technology, Erode, Tamil Nadu, India (2015) "Experimental Investigation on the Mechanical Properties of Jute/Sisal/Glass and Jute/Banana/Glass Hybrid Composite Materials"

2. José A. Rabi, Sérgio F. Santos, Gustavo H. D. Tonoli and Holmer Savastano Jr. Faculty of Animal Science \& Food Engineering (FZEA), University of São Paulo (USP) Avenida Duque de Caxias Norte, 225,13635-900, Pirassununga SP, Brazil (2009). "AGRICULTURAL WASTES AS BUILDING MATERIALS: PROPERTIES, PERFORMANCE AND APPLICATIONS"

3. Christos Babu \& Kalesh K K, M. Tech Scholar, Department of Mechanical Engineering, Sree Buddha College of Engineering, University of Kerala, India (2015). "Development of a Natural Fibre Reinforced Composite for Safety and Construction Applications"

4. Nilsson and Kavin G.(1975), 'Study on flexural and toughness behavior of natural fibres in concrete', Journal of Composite Structures, Vol. 23,pp. 95-115.

5. Kuruvilla Joseph., George Leslie and Khosrow Ghavami.(1999), 'The use of Sisal Fibre as reinforcement in cement based composites', Revista Brasileira de Engenharia Agrícola e Ambiental, Vol. 12, pp. 245-256.

6. Augustine Uche Elinwa and Stephen Pinder Ejeh. (2003), 'Characterization of Sisal Fibre Reinforced Concrete', Journal of Applied Sciences, Vol. 3, pp. 23-30.

7. Jagannatha Reddy H.N. and Tara Sen. (2007), 'Efficiency of Thermally Conditioned Sisal FRP Composite on the Shear Characteristics of Reinforced Concrete Beams', Research Journal of Engineering Sciences, Vol. 5, pp. $230-245$.

8. Kawkab Habeeb Al Rawi.(2009), 'Effect of adding sisal fiber and iraqi bauxite on some properties of concrete', Journal of Applied Mechanics, Vol. 9, pp. 45-52.

9. G. Ramakrishna, T. Sundararajan and S. Kothandaraman Department of Civil Engineering, Pondicherry Engineering College, Pondicherry, India24 (2011)STRENGTH OF CORRUGATIONS OF A ROOFING SHEETS REINFORCED WITH SISAL FIBRES

10. Tara Sen , H.N. Jagannatha Reddy (2013) "Strengthening of RC beams in flexure using natural jute fibre textile reinforced composite system and its comparative study with CFRP and GFRP strengthening systems"

11. Athiappan., Vijaychandrakanth.(2014) Experimental Study on Flexural Behavior of Sisal Fibre in Reinforced Concrete Beam

12. Ms. Shweta A. Sajjanshetty, Ms. Rupali B. Kejkar, Ms. Supriya S. Choudhari, Mr. Vinayak B. Kale (2014) Flexural Behavior of Strengthened and Repaired R.C. Beams by using Steel and Coir Fiber Concrete Jacket.

13. Kotresh Sardar, Dr. T. Rangaswamy, Shivakumar (2014) Fabrication and Investigation of Bending Test on Hybrid (Sisal and Banana) Fiber Reinforced Polyester Composite Material

14. M. R. Sanjay,G. R. Arpitha, L. Laxmana Naik, K. Gopalakrishna, B. Yogesha(2016) Applications of Natural Fibers and Its Composites: An Overview.

15. Arpitha G R, Sanjay M R, L Laxmana Naik, B Yogesha Department of Mechanical Engineering, Malnad College of Engineering, Hassan, Karnataka, India (2014). 